Open Access

\title{
Investigating the use of a lecture capture system within pharmacy education: Lessons from an undergraduate pharmacy program at Qatar University
}

\author{
Farhat Naz Hussain *i(D, Reem Al-Mannai, Mohammad Issam Diab and Abdelali Agouni*
}

\author{
*Correspondence: fhussain@qu.edu. \\ qa; aagouni@qu.edu.qa \\ College of Pharmacy, QU Health, \\ Qatar University, PO Box 2713, \\ Doha, Qatar
}

\begin{abstract}
Video lecture capture is one of the most attractive e-tools that has been introduced to support students learning and assist with grasping difficult concepts. A variety of benefits is offered through this system introduced at our institution nearly a decade ago. We evaluated lecture capture viewings for professional undergraduate pharmacy courses in the Fall and Spring semesters over three academic years and analyzed data for one cohort of students. Each course within the pharmacy program was analyzed and viewing figures downloaded through the Echo360 management system. The average number of views per lecture, per semester was summarized. We observed that junior students viewed lecture capture most frequently with the number of views highest at the beginning of the academic year (Fall semester). Analysis of 18 courses which occurred 48 times over the three academic years studied, showed that 21 course occurrences had an average number of views per lecture equal to or higher than the number of students enrolled in the course, indicating that only $44 \%$ of courses had on average, at least, one student viewing each lecture recording. Of particular note, year 1 students had the highest percentage of courses viewed by a number equal to or higher than students enrolled ( 9 occurrences out of 16 or $56 \%$ ), followed by year 2 students ( 9 occurrences out of 21 or 43\%), and finally year 3 students (3 occurrences out of 11 or $27 \%$ ). This pattern of lecture recording viewing was further underscored by longitudinally following-up the class of 2020 (24 students) over three academic years. To ensure optimal use of the system by both students and faculty for a multitude of learning and teaching styles and methods, we propose to implement professional development sessions for faculty to showcase the advantages of the lecture capture system and maximize the benefits from its availability. Further quantitative and qualitative studies are warranted to fully grasp the motivations for use, attitudes and perceptions towards the system.
\end{abstract}

Keywords: Lecture capture, Technology-enhanced learning, higher education, Pharmacy 


\section{Introduction}

The use of technology to support teaching and learning is evolving rapidly, with multiple technologies currently used to assist teaching and introduce active learning in the classroom setting (Hussain \& Wilby, 2019). Technology-enhanced learning (TEL) is now strongly anchored in the learning and teaching strategies of an increasing number of higher education institutions worldwide because it fosters a more collaborative, active, self-centered and adaptive attitude towards learning experience (Casanova, Moreira \& Costa, 2011). In this context, video lecture capture is one of the most attractive e-tools that has been introduced to support students learning and assist with grasping difficult concepts (Schnee et al., 2019; Marchand, Pearson \& Simon, 2014). This technology allows live recording of audio and visual content, including instructors and all educational material they may project on screens. The use of this technology in undergraduate programs at medical and pharmacy education institutions enables students to choose the location, pace and frequency of studying while enabling them to focus on live lectures rather than concentrate on notetaking, with the assurance that the lecture will be available to view in full after the session is complete or to review the content of missed lectures (Burton, Ma, \& Grayson, 2017; Franklin, Gibson, Samuel, Teeter, \& Clarkson, 2011; Bacro, Gebregziabher, \& Fitzharris, 2010). However, there is still no clear agreement about the impact of using lecture capture technologies on academic performance and outcomes with some evidence suggesting improved grades for students, whereas others reporting no impact (Franklin et al., 2011; Maynor, Barrickman, Stamatakis, \& Elliott, 2013; Stroup, Pickard, \& Kahler, 2012; Fernandes, Maley, \& Cruickshank, 2008).

Lecture capture technology should not be viewed only as a tool that merely supports students' learning outside of the classroom setting, but rather as an essential partner in the development and refinement of innovative teaching and learning methods. The availability of lecture capture systems has dramatically contributed to the development and expansion of use of certain types of active learning strategies such as flipped classrooms, that have been found to leave a positive impact on students' learning outcomes (Tune, Sturek, \& Basile, 2013). In flipped classrooms, basic factual material about the subject is provided in advance to students through recorded videos or other methods of delivery followed by a face-to-face session where the time is mainly dedicated to application and critical thinking activities. Readily available, lecture captures facilitate the implementation and delivery of flipped classrooms. Students attending flipped classrooms were reported to outperform those taking classical lecture styles for their final letter grade (DeRuisseau, 2016).

Adoption and use of lecture capture systems is not without issues and one in particular is highlighted by many educators, its impact on class attendance. However, there is no consensus on the impact of availability of lecture recordings on class attendance with some studies reporting an adverse effect (Traphagan, Kucsera, \& Kishi, 2010) while others reporting no negative impact on student attendance to classes (Franklin et al., 2011; Gupta \& Saks, 2013). However, the dynamics of viewing and use of lecture recordings have not been explored in undergraduate curricula where attendance to lectures is compulsory by University policy.

With regards to pharmacy undergraduate education, major international program accrediting bodies such as the Accreditation Council for Pharmacy Education (ACPE) 
and the Canadian Council for Accreditation of Pharmacy Programs (CCAPP) do not explicitly require the use of lecture capture technology in current classroom settings; however, the implementation of a variety of teaching and learning methods, including actively engaging learners and promoting student responsibility for self-directed learning, is a requirement of accreditation standards. Although it is currently unknown the number of pharmacy programs worldwide recording and posting lectures online, it was reported by the American College of Clinical Pharmacy (ACCP) that $70 \%$ of pharmacy programs were using lecture capture technology in pharmacy schools across the United States (Hamilton, Franks, Heidel, McDonough, \& Suda, 2016).

The College of Pharmacy, Qatar University, where the Bachelor of Science in Pharmacy (BSc Pharm) program is CCAPP-accredited since its inception in 2008, introduced the Echo360 lecture capture platform nearly a decade ago and was the first College at the University to introduce this technology. Audio and video lecture capture is recorded through the Echo360 system with an overlay of the presented PowerPoint presentation slides for all regularly scheduled classes. A file is created and posted online $24 \mathrm{~h}$ after the session is complete through the virtual learning environment (VLE) platform Blackboard 9.1. Students have access to the video link of their lectures in addition to all archived lectures from previous academic years, until graduation. There are no limits placed on the number of times a student can view the capture and students may view all or a selected portion of the link. An administrative user may access the Echo360 report to monitor downloaded data for individual lecture recordings, specifying the time and date of the lecture and the number of times this lecture has been viewed.

Although video lecture capture was introduced at our institution nearly a decade ago, no studies have been conducted to assess the use or effectiveness of this technology. The purpose of this study was to evaluate lecture capture viewings for professional undergraduate pharmacy courses in the Fall and Spring semesters over three consecutive academic years. A secondary objective was to analyze longitudinally the data for one specific cohort (class of 2020) whose data was available for six consecutive academic semesters. Understanding the quantitative patterns of use of this technology at the College across courses and years may identify barriers for its optimal exploitation and pave the way for a future program of work to maximize the benefits from this educational technology. One key specificity of this study is that attendance to classes is mandatory by the University policy, which is also a very common practice in Universities of the region. If a student fails to attend more than $25 \%$ of classes for a specific course within one semester, the student will receive a failing grade for that course, thus ensuring optimal student attendance. This may help dissociating our observations for lecture recording viewings from the widely reported issue of students using recordings as a replacement to physical attendance of classes (Franklin et al., 2011; Gupta \& Saks, 2013). To the best of our knowledge, this is the first study of its kind in the Middle East and North Africa (MENA) region to investigate the use of this type of TEL for a health program in higher education.

\section{Methods}

\section{Study population and methods of data collection}

Lecture capture viewing figures from undergraduate pharmacy students at the College of Pharmacy, Qatar University (class of 2018 - class of 2022) were analyzed over three 
academic years (AY) (6 semesters). The College of Pharmacy offers a BSc Pharm degree consisting of one pre-pharmacy and four professional years. For our study, eighteen courses were included for analysis, professional year 1 (P1) (6 courses), professional year 2 (P2) (8 courses) and professional year 3 (P3) (4 courses). During the period analyzed, these courses occurred a total number of 48 times; this is referred to throughout the text as "course occurrences". Table 1 shows the course name, course number and the semester at which it occurred. A total of 926 lectures were analyzed and viewing figures were averaged per lecture. Courses which occurred consecutively within the professional years between the Fall and Spring semester, whether integrated or standalone, and had at least two years of data available, were included (Table 2). The number of students enrolled in each course for each year can been seen in Table 2. Courses that were independent and did not occur as a series, those that did not have enough data, or those in which the nature of the course rendered it unsuitable for recording (i.e., group discussion/lab work) were excluded from the analysis.

Access to view lecture capture viewing figures was granted to four investigators using the Echo360 video management lecture capture program (FN, AAG, RM, MD). Two investigators (FN, RM) analyzed each course within the pharmacy program and downloaded viewing figures onto a Google Sheet. Data was available per course and per

Table 1 Courses included in analysis of lecture capture views

\begin{tabular}{|c|c|c|c|}
\hline Course Name & $\begin{array}{l}\text { Course number } \\
\text { (PHAR) }\end{array}$ & Fall/Spring & $\begin{array}{l}\text { Number of } \\
\text { lectures analyzed }\end{array}$ \\
\hline \multicolumn{4}{|l|}{$\mathrm{P} 1$} \\
\hline Medicinal Chemistry I & 200 & Fall & $52^{\mathrm{a}}$ \\
\hline Medicinal Chemistry II & 201 & Spring & 82 \\
\hline Foundations of Pharmacology \& Pharmacotherapeutics I & 220 & Fall & $22^{\mathrm{a}}$ \\
\hline Foundations of Pharmacology \& Pharmacotherapeutics II & 221 & Spring & 34 \\
\hline Pharmacy \& Healthcare I & 230 & Fall & 45 \\
\hline Pharmacy \& Healthcare II & 231 & Spring & 29 \\
\hline \multicolumn{4}{|l|}{ P2 } \\
\hline Pharmacy Research, Evaluation \& Presentation Skills I & 305 & Fall & $25^{\mathrm{a}}$ \\
\hline Pharmacy Research, Evaluation \& Presentation Skills II & 306 & Spring & 30 \\
\hline Pharmaceutics II & 310 & Fall & $24^{\mathrm{a}}$ \\
\hline Pharmaceutics III & 311 & Spring & 48 \\
\hline Pharmacokinetics I & 316 & Fall & $23^{\mathrm{a}}$ \\
\hline Pharmacokinetics ॥ & 317 & Spring & 39 \\
\hline $\begin{array}{l}\text { Integrated courses (IC) (Pathophysiology, Pharmacology } \\
\text { and Pharmacotherapeutics) }\end{array}$ & IC 1 & Fall & 94 \\
\hline $\begin{array}{l}\text { Integrated courses (IC) (Pathophysiology, Pharmacology } \\
\text { and Pharmacotherapeutics) }\end{array}$ & IC 2 & Spring & 125 \\
\hline \multicolumn{4}{|l|}{ P3 } \\
\hline Pharmacy Research, Evaluation \& Presentation Skills III & 405 & Fall & $19^{\mathrm{a}}$ \\
\hline Pharmacy Research, Evaluation \& Presentation Skills IV & 406 & Spring & 26 \\
\hline $\begin{array}{l}\text { Integrated courses (Pathophysiology, Pharmacology and } \\
\text { Pharmacotherapeutics) }\end{array}$ & IC 3 & Fall & 114 \\
\hline $\begin{array}{l}\text { Integrated courses (IC) (Pathophysiology, Pharmacology } \\
\text { and Pharmacotherapeutics) }\end{array}$ & IC 4 & Spring & 95 \\
\hline
\end{tabular}


Table 2 Courses analyzed per cohort of students

\begin{tabular}{|c|c|c|}
\hline Class & $\begin{array}{l}\text { Courses analyzed } \\
\text { (number of students enrolled) }\end{array}$ & Notes \\
\hline 2018 & $\begin{array}{l}\text { PHAR } 405 \text { (25) versus PHAR } 406 \text { (24) } \\
\text { IC3 (25) versus IC4 (24) }\end{array}$ & P3 courses \\
\hline 2019 & $\begin{array}{l}\text { PHAR } 305 \text { (16) versus PHAR } 306 \text { (14) } \\
\text { PHAR } 310 \text { (23) versus PHAR } 311 \text { (16) } \\
\text { PHAR } 316 \text { (16) versus PHAR } 317 \text { (15) } \\
\text { IC1 (18) versus IC2 (18) } \\
\text { PHAR } 405 \text { (15) versus PHAR } 406 \text { (15) } \\
\text { IC3 (15) versus IC } 4 \text { (15) }\end{array}$ & $\mathrm{P} 2$ and $\mathrm{P} 3$ courses \\
\hline 2020 & $\begin{array}{l}\text { PHAR } 200 \text { (25) versus PHAR } 201 \text { (25) } \\
\text { PHAR } 220 \text { (25) versus PHAR } 221 \text { (25) } \\
\text { PHAR } 230 \text { (25) versus PHAR } 231 \text { (25) } \\
\text { PHAR } 305 \text { (25) versus PHAR } 306 \text { (25) } \\
\text { PHAR } 310 \text { (25) versus PHAR } 311 \text { (24) } \\
\text { PHAR } 316(25) \text { versus PHAR } 317(25) \\
\text { IC1 (24) versus IC2 (24) } \\
\text { PHAR } 405 \text { (24) versus PHAR } 406 \text { (24) } \\
\text { IC3 (22) versus IC } 4 \text { (22) }\end{array}$ & $\mathrm{P} 1, \mathrm{P} 2$ and $\mathrm{P} 3$ courses \\
\hline 2021 & $\begin{array}{l}\text { PHAR } 200 \text { (31) versus PHAR } 201 \text { (31) } \\
\text { PHAR } 220 \text { (31) versus PHAR } 221 \text { (31) } \\
\text { PHAR } 230 \text { (31) versus PHAR } 231 \text { (31) } \\
\text { PHAR } 305 \text { (31) versus PHAR } 306 \text { (29) } \\
\text { PHAR } 310 \text { (30) versus PHAR } 311 \text { (29) } \\
\text { PHAR } 316 \text { (30) versus PHAR } 317 \text { (28) } \\
\text { IC1 (33) versus IC2 (33) }\end{array}$ & $\mathrm{P} 1$ and $\mathrm{P} 2$ courses \\
\hline 2022 & $\begin{array}{l}\text { PHAR } 200 \text { (31) versus PHAR } 201 \text { (31) } \\
\text { PHAR } 220 \text { (31) versus PHAR } 221 \text { (31) } \\
\text { PHAR } 230 \text { (31) versus PHAR } 231 \text { (31) }\end{array}$ & P1 courses \\
\hline
\end{tabular}

$\mathrm{P} 1=$ professional year $1, \mathrm{P} 2=$ professional year $2, \mathrm{P} 3=$ professional year $3 ; \mathrm{IC}=$ integrated courses

lecture with viewing figures available for the majority of courses. The data was verified and analyzed by two further investigators (AAG, MD), then pooled for statistical analysis. The average number of views per course, per semester was recorded and summarized.

\section{Ethics}

There was no interaction with human subjects for study purposes therefore ethical review was not required. However, permission to use lecture capture data was obtained from the college administration for publication purposes of these results.

\section{Statistics and data analysis}

Data are expressed as views per lecture capture as mean \pm SEM (standard error of the mean). Statistical analyses were performed using a one-way analysis of variance (ANOVA) followed by Tukey's post hoc test or using two-way ANOVA and subsequent Bonferroni post hoc test, as appropriate. The normality of data was tested each time using D'Agostino \& Pearson and Shapiro-Wilk normality tests. $P<0.05$ was considered as statistically significant. Analysis was conducted using GraphPad Prism 7.0e software.

\section{Results}

\section{Comparison of lecture capture views between fall and spring courses}

The academic year begins with the Fall semester followed by the Spring semester. Over the course of three academic years (16AY, 17AY and 18AY) and six semesters, a 
marginally higher number of lecture capture views was observed throughout the Fall semester within different professional years; however, a decrease in number of views was evident for the consecutive courses during the Spring semester (Figs. 1, 2 and 3).

P1 courses had a higher number of average views particularly in the Fall semester, which then declined in Spring courses (Fig. 1). The most significant differences in views between Fall and Spring semesters were observed between PHAR200 and PHAR201 $(P<$ 0.001; Fig. 1a) in 16AY and between PHAR220 and PHAR221 in 17AY and 18AY $(P<$ 0.01; Fig. 1b). A non-significant trend for decrease was also observed for the number of views between PHAR230 (Fall) and PHAR231 (Spring) in 16AY and 17AY (Fig. 1c). The average number of views in P1 courses was equal to or higher than the number of students enrolled (24 or 33 students depending on the academic year) for 9 course occurrences delivered over the 3 academic years studied (a total of 6 P1-courses that occurred 16 times during this period were analyzed), indicating that each student viewed each recording for these courses, at least, once. Interestingly, 7 out of these course occurrences were delivered in a Fall semester (Fig. 1). The highest average number of views (65 \pm 9 views per lecture) was observed for a Fall semester course, PHAR200 delivered in 16AY (24 students enrolled), whereas the lowest Fig. (11 \pm 2 views per lecture) was observed for a Spring course, PHA201 delivered in 18AY (33 students enrolled) (Fig. 1a).

The average number of views per lecture for P2 courses ranged between $10 \pm 2$ (PHAR311, 16AY) and $35 \pm 3$ (IC2, 18AY) which is lower compared to figures observed in P1 courses; however, similarly to P1, the number of views were higher in the Fall semester (Fig. 2). Out of the 8 courses and 21 occurrences we have studied for P2 across 6 academic semesters, 9 course occurrences had an average number of views equal to

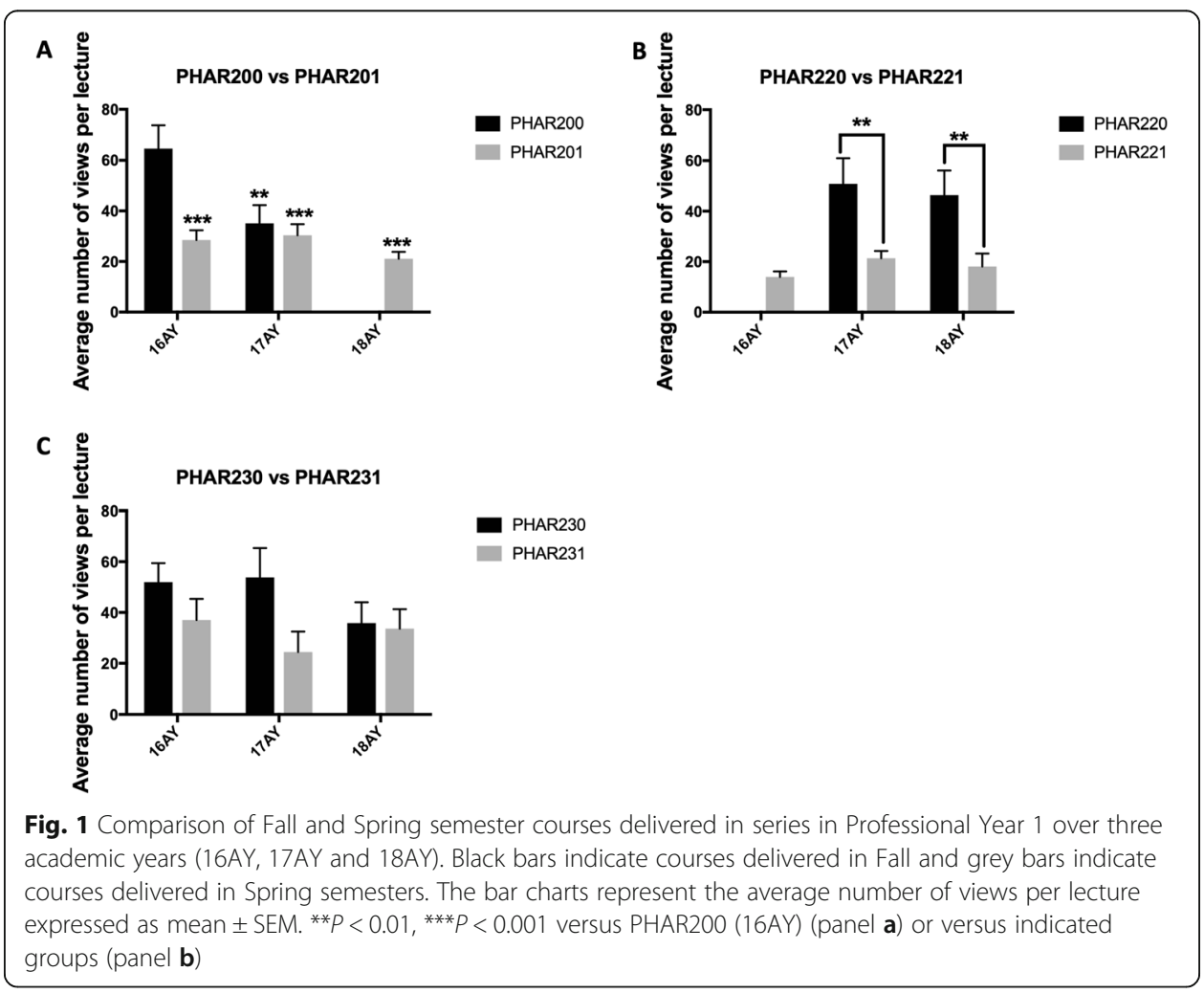




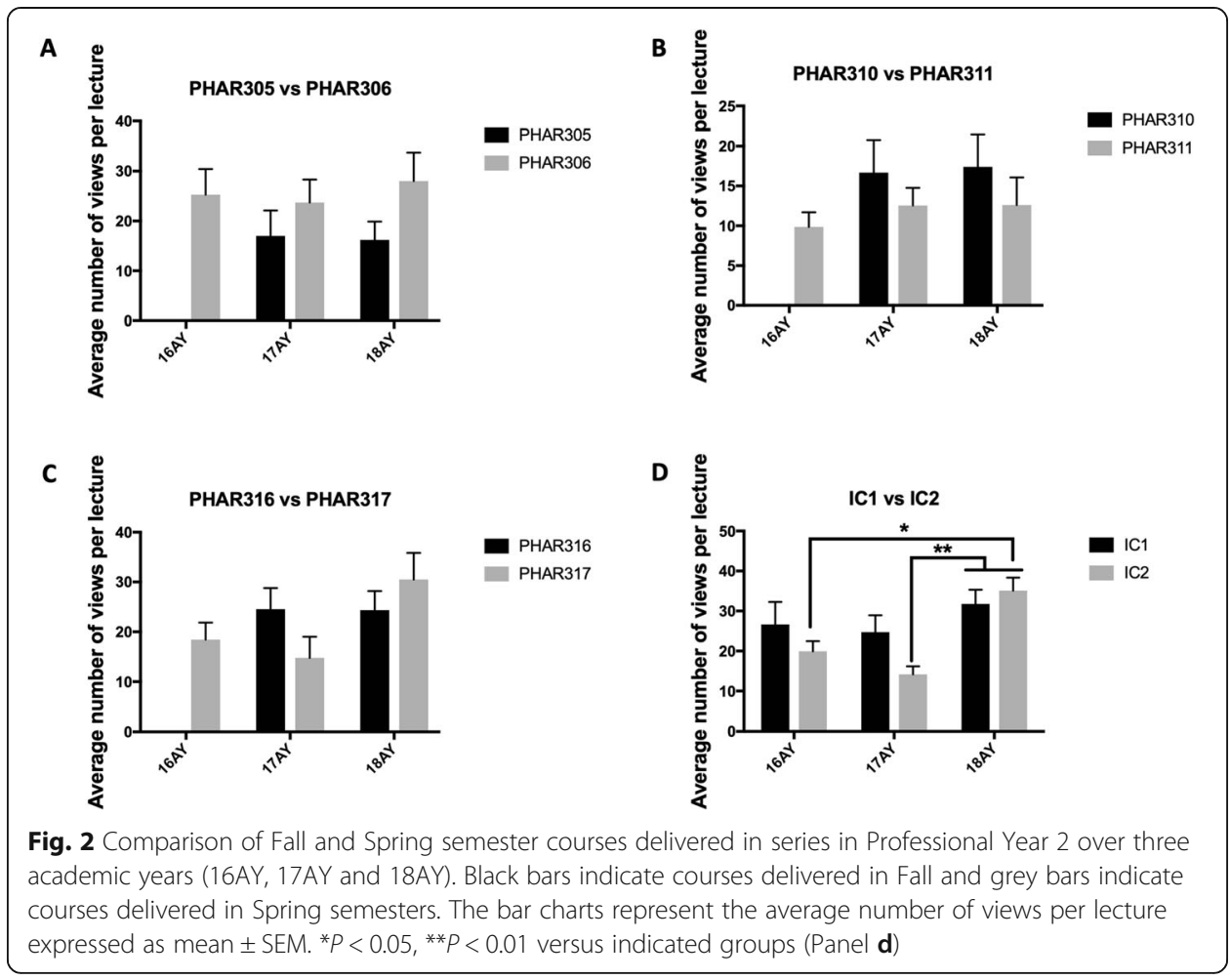

or higher than the number of students enrolled (15-33 students depending on the academic year) (Fig. 2).

For P3, data was only available for 4 courses which occurred 11 times during the study period (6 academic semesters). The average number of views per lecture for P3 courses ranged between $9 \pm 3$ (PHAR405, 17AY) and $39 \pm 7$ (IC3, 16AY) which is lower compared to figures observed in P1 courses (Fig. 3). Out of the 11 course occurrences we have studied for P3 across 3 academic years, 3 course occurrences only had an average number of views equal to or higher than the number of students enrolled (15-25 students depending on the academic year) (Fig. 3).

The integrated course (IC) is a combination of three different courses within the pharmacy curriculum - pathophysiology, pharmacology and pharmacotherapy. These courses

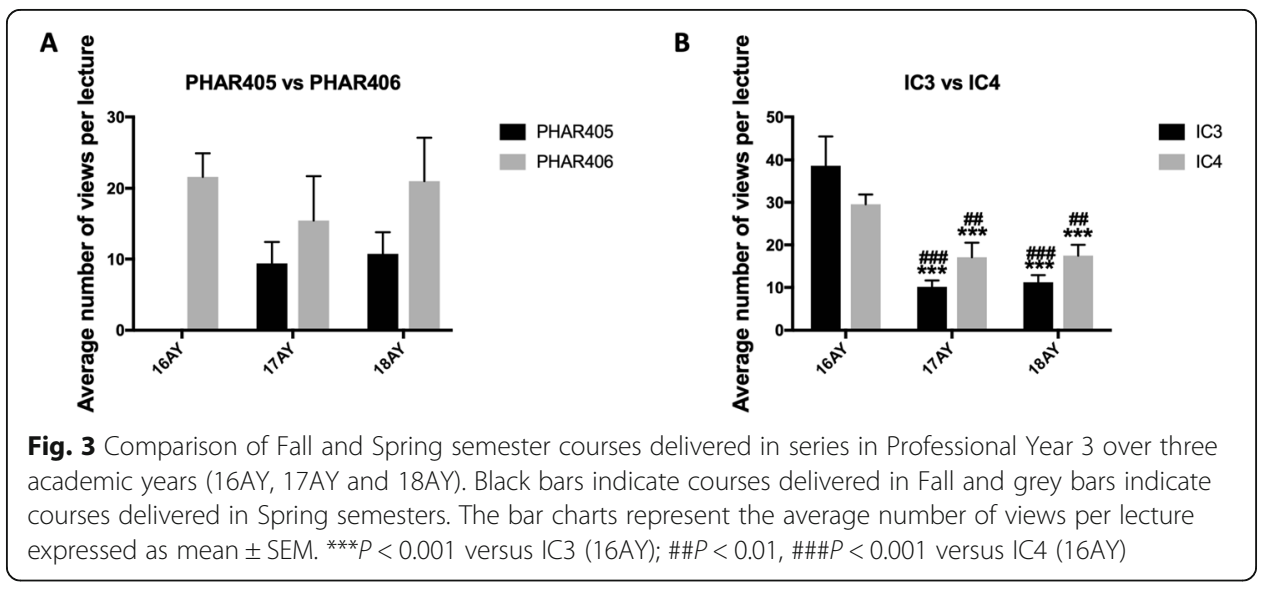


are synchronized in time and lectures for each course are delivered sequentially for each topic and the lecture recordings are then uploaded to the VLE as a single file for lectures from the three courses for each topic. With specific focus on these IC series, the analysis of the average number of views, showed that IC1 and IC2 taken in P2 (Fig. 2d) had no statistical difference between Fall and Spring semesters across all 3 academic years studied (16AY, 17AY, 18AY); however, the average number of views for both IC1 and IC2 were significantly higher in 18AY compared to 16AY and 17AY (Fig. 2d). With regards to P3 IC, both IC3 and IC4 courses showed a statistically significant decrease in the average number of views in 17AY and 18AY compared to 16AY; however, no statistically significant difference was observed between Fall and Spring semesters in all 3 academic years studied (16AY, 17AY, 18AY) (Fig. 3b).

Overall, we have analyzed here 18 courses in total which occurred 48 times during the study period (6 consecutive semesters) and found that among of these, 21 occurrences had an average number of views per lecture equal to or higher than the number of students enrolled in the course, indicating that during the period studied only $44 \%$ of courses had on average, at least, one student viewing each lecture recording. Of particular note, P1 students had the highest percentage of courses viewed by a number equal to or higher than students enrolled (9 course occurrences out of 16 or 56\%), followed by P2 students ( 9 course occurrences out of 21 or 43\%), and finally P3 students ( 3 course occurrences out of 11 or $27 \%$ ). These data support the conclusion that junior students tend to view more lecture recordings.

Analysis of lecture capture views for class of $\mathbf{2 0 2 0}$ over three consecutive academic years Courses for the class of 2020 were analyzed for three consecutive academic years (P116AY, P2-17AY and P3-18AY) (Fig. 4). In their P1, students accessed more often the Echo360 lecture recordings (range from $14 \pm 2$ to $65 \pm 9$ views) with an average number of views for 4 courses out of 6 studied equal to or higher than the number of students enrolled (24 students). The PHAR200 course delivered in the Fall semester showed the highest viewing Figs. (65 \pm 9 views) compared to all other courses and was significantly higher compared to the number of viewings of PHAR201 delivered in Spring $(p<$ 0.0001) (Fig. 4a). In P2, the average number of views declined compared to P1 (range from $13 \pm 2$ to $25 \pm 4$ views) with only 3 courses out of 8 studied showing an average number of views equal to or higher than the number of students enrolled (24 students) (Fig. 4b). In P3, the average number of views further declined compared to both P1 and P2 (range from $11 \pm 2$ to $21 \pm 6$ views) with none of the 4 courses studied showing an average number of views equal to or higher than the number of students enrolled (24 students) (Fig. 4c).

\section{Discussion}

The purpose of this study was to evaluate lecture capture viewings for professional undergraduate pharmacy courses in the Fall and Spring semester over three academic years (6 semesters). A secondary objective was to analyze longitudinally the data for one specific cohort (class of 2020) whose data was available for three consecutive academic years. To the best of our knowledge, this is the first study of its kind in the 


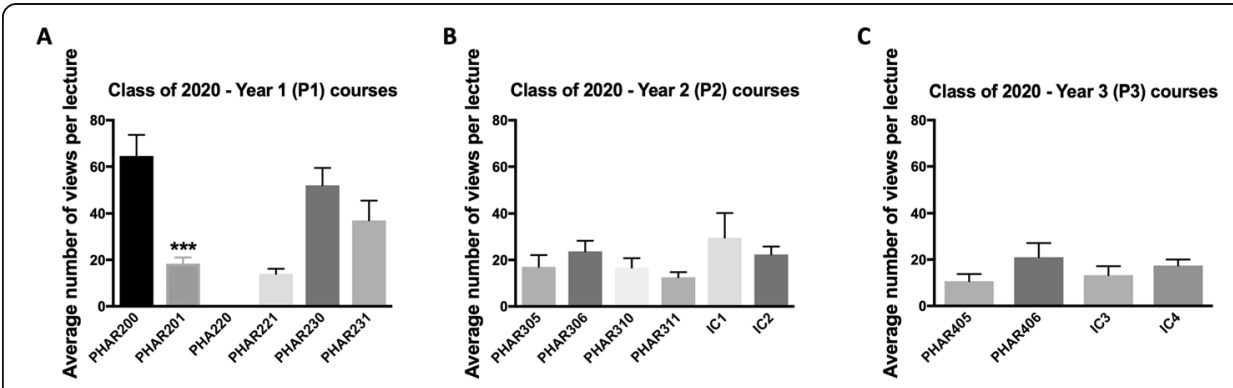

Fig. 4 Comparison of Fall and Spring semester courses over three academic years in Class of 2020. The bar charts represent the average number of views per lecture expressed as mean \pm SEM. ${ }^{* * *} P<0.001$ versus PHAR200 (panel a)

MENA region to investigate the use of this type of TEL for a health program in higher education.

Lecture capture technology offers several benefits to faculty and students including preparing and studying for assessments, support for students who are absent from live lectures and assisting students in understanding difficult concepts (Freeman, Schrimsher, \& Kendrach, 2006; Marchand, Pearson, \& Albon, 2014; Maynor et al., 2013). Given that university students in this era are a digital generation who have been raised surrounded by technology (Corrin, 2010), the investigators postulated that the viewing figures for a number of courses would be high and consistent throughout the academic years. Overall, this study showed that students view lecture capture only for selected courses, and generally, the views for the first half of the academic year (Fall semester) are higher compared to that of the second half (Spring semester). The courses taken in P1 were the most viewed for lecture capture, with viewing figures declining as the academic years progressed to reach a steady level.

A key finding of this study is that an overwhelming majority of junior students consistently viewed lecture capture multiple times on average with the number of views higher at the beginning of the academic year. However, senior students viewed lecture capture less often with one view per lecture per student on average. A study by Burton et al. (Burton et al., 2017) supports our finding and reports that the percentage of students viewing lecture capture levelled off by the second half of the academic year. A high number of views during the Fall semester may be due to student's initial motivation at the beginning of the academic year; however, as the year progresses students may perceive the time spent on viewing lecture capture in a less positive manner. Students may prefer to spend more time studying through other methods such as lecture notes and case-based practical problems. Other factors that may influence the number of views include individual or group viewings, with the latter reducing the number of recorded viewings. Changes in the curriculum or instructor may also play a role in the pattern of views witnessed with these courses. Overall, the number of views for the lecture capture program appeared lower than the investigators had expected.

The IC series is a combination of three different courses within the pharmacy curriculum - pathophysiology, pharmacology and pharmacotherapy. These courses are synchronized in time and lectures for each course are delivered sequentially for each topic and the lecture recordings are then uploaded to the VLE as a single file for lectures from the 3 courses for each topic. There was a trend for a decrease in the number 
of views between Fall and Spring in P2; however, for P3 there was rather a trend for increase. This could be driven by several factors chiefly the nature of topics that might be perceived as harder by students for the P3 level courses. Furthermore, one can speculate that the academic ability of students can also affect the number of views as it has been reported that students who have a lower academic ability tend to view and benefit from the lecture capture more often (Owston, Lupshenyuk, \& Wideman, 2011). Of special note, the motivation for viewing the combined lecture recordings for this course may be driven by any of the three courses and hence it is difficult to assess whether it is the overall or the individual course-specific perceived difficulty that is driving these patterns of viewing.

Analysis of viewing figures for the class of 2020 throughout three consecutive academic years showed that P1 (16AY) courses have the most views, when compared to other courses in P2 (17AY) and P3 (18AY), this is in contrast to the findings shown by Chester et al. (Chester, Buntine, Hammond, \& Atkinson, 2011) who concluded that second and third year students found lecture capture to be more useful than first year students; however, this study analyzed perceptions without quantitative data on viewing figures. The difference within these findings may also be due to the undergraduate degree program that is being analyzed. Chester et al. analyzed students over seven undergraduate courses; however, our study focuses on one undergraduate program, Bachelor in Pharmacy. Within our setting, we postulate that students entering P1 from prepharmacy may have a perception of lecture content difficulty and a transition period moving towards professional pharmacy courses. As a result, students may be more inclined to view lecture capture to grasp difficult concepts or revisit sections of lectures to aid their understanding. Novelty of the technology may also play a role in the initial motivation to view lecture capture. To date, there is no study examining the quantitative usage of lecture capture between junior and senior students and hence our current study provides novel insight on the dynamics of use of this technology across the academic years by undergraduate pharmacy students.

A systematic review conducted by O'Callaghan et al. (O'Callaghan, Neumann, Jones, \& Creed, 2017) found that students have a positive perception towards lecture capture and agreed that it enhanced the effectiveness of their learning; however, almost half of all students analyzed in the review suggested that lecture capture should not be used as a substitution for face-to-face learning. Students cited benefits of face-to-face learning including immediate feedback from questions and motivation to learn whilst attending the lecture. At our institution lecture capture does not replace, but rather supplements live lectures, providing a backup option to allow students to view the lecture in sections or in full after the lecture has taken place at their own pace. Furthermore, the availability of archived lectures until graduation allows students to view content delivered for a specific lecture in previous year(s) in advance of the sessions of the current academic year. Altogether, given the benefits of this technology for students outlined here, it was indeed very surprising to observe that the number of views per lecture is in general low and declines over the years of the program. For instance, most of the courses had on average 20 views per lecture, which means that less than one student per class had viewed the lecture (class size in general 24-30 students - Table 2). Therefore, further research is warranted to assess student's perceptions of lecture capture within our institution to qualitatively determine barriers for a wider use of this technology. 
Despite the great efforts to ensure the systematic availability of Echo360 lecture capture technology across all courses in our pharmacy program, our current study has identified a gap in the use of this TEL tool. Therefore, additional research is required to fully understand the reasons behind this gap and to implement remedial actions to ensure full advantage of this process to enhance learning experience and teaching at the college. One way forward to encourage the use of this technology is to implement development sessions for both students and faculty. This is particularly important because the College of Pharmacy was the first Health College at Qatar University using this technology to enhance students' learning experience.

A development session highlighting the benefits of lecture capture and how to maximize the benefit of using of the Echo360 system may increase the number of lecture capture viewings. This could apply more importantly to P1 students who may have never used the lecture capture system before. The impression students receive when starting the pharmacy degree will last throughout the academic years; therefore, an early curriculum development session showing the key learning benefits of the system may incline students to use lecture capture more frequently throughout the program. A development session will also allow students and faculty to comfortably navigate through the possibilities offered by the system. Faculty development, especially for new members, may encourage use of this educational resource that is already widely available. For example, the lecture capture resource can be beneficial if faculty are taking a 'flipped-classroom' approach thus having an effect on student engagement (Marchand, Pearson \& Simon, 2014). In addition, the system can be used by new faculty to review past lectures and develop their own teaching skills. Furthermore, existing faculty can also benefit from the system by reviewing their own previously delivered lectures as a professional development tool to revise lecture content (e.g., review material and explanations to difficult sections), monitor body language and improve communication skills in the next cycle of lectures.

Another benefit of this system that should be highlighted is for peer-observation of teaching; a faculty member can benefit from the input and guidance of experienced faculty members after they have viewed samples of previous lectures (delivered spontaneously) instead of the traditional peer-observation process that requires observer(s) to physically attend a selected lecture(s). Furthermore, promotion of lecture capture by faculty members may encourage students to spend time viewing previous lectures. From an equal opportunity and widening participation point of view, this system can provide an advantage to students who are unable to understand an instructor's accent or those with special learning needs such as students who may be hard of hearing. This is particularly important especially that some students with certain special needs do not always disclose them to the student learning support office. To fully utilize the system, the introduction of captions may help overcome some of these barriers (Dommeyer, 2017). This is now facilitated by the availability of automated tools and software to introduce closed captions.

Student attendance in class is a concern raised by faculty members when using lecture capture (O'Callaghan et al., 2017); however, within our institution at Qatar University, class sizes are small (less than 30 students per class) and attendance to all professional pharmacy courses is mandatory, a policy set by the University. If a student fails to attend more than $25 \%$ of classes for a specific course within one semester, the 
student will receive a failing grade for that course, thus ensuring optimal student attendance. A multitude of studies have been conducted in this regard and many studies have concluded that lecture capture does not affect student attendance, whereby students use the recordings to supplement or enhance lecture material rather than replace live lectures (McLean \& Suchman, 2016; Copley, 2007; Traphagan et al., 2010).

The findings of this study should be considered, however, in light of some limitations. The system does not permit tracking of individual use so we cannot distinguish multiple downloads/views from a single user. The number of views for each course is a collective figure including students and faculty, although we may speculate that the majority of views come from students. Furthermore, we cannot determine which subsection or the length of time an individual viewed the lecture capture. The integrated series data is a combination of three courses (pathophysiology, pharmacology and pharmacotherapy); therefore, conclusions cannot be made for the number of views on each individual course delivered in these integrated series. A number of courses were excluded from the study due to the nature of delivery resulting in no lecture capture data, these included courses that require group discussion or lab work. Courses that had missing data (more than two academic years) were also excluded. There can be multiple reasons for missing data, the instructor may not have turned the microphone on to allow for recording, or the audio may be distorted due to improper placement of the microphone, and technical issues can result in the lecture capture system being shut down (updates, classroom schedule changes, battery replacement issues) etc. These issues can be addressed in development sessions aimed at faculty members and staff involved in the coordination of the process. Overall, while we consider that our experience in the use of video capture technology is quite unique among other internationally-accredited pharmacy programs in the MENA region both by its systematic and long history of use, it is also fair to consider that our experience can also be extrapolated to other pharmacy programs across the world owing to the close and long-term collaboration of the pharmacy program at our institution with CCAPP and the stringent implementation of its international standards for pharmacy education.

\section{Conclusion}

Our findings suggest that the lecture capture system which is wholly operational within our College for nearly a decade is primarily utilized by junior pharmacy students and most viewed at the beginning of the academic year (Fall semester), hence, further studies must be conducted to fully understand why. To ensure optimal use of the system by both students and faculty for a multitude of learning and teaching styles and methods, we propose to implement professional development sessions for faculty to showcase the advantages of the lecture capture system and maximize the benefits from its availability.

This study needs to be complemented with additional quantitative and qualitative studies to fully grasp the motivations for use, attitudes and perceptions towards the system. Questionnaires for students and faculty will be developed and implemented to gain more insight into patterns of use of the system. In addition, focus groups and semi-structured interviews with both students and faculty may help us in devising a bespoke action plan to tackle the identified barriers for a wider use of this technology. 


\section{Abbreviations}

ACCP: American College of Clinical Pharmacy; ACPE: Accreditation Council for Pharmacy Education; AY: Academic Years; BSc Pharm: Bachelor of Science in Pharmacy; CCAPP: Canadian Council for Accreditation of Pharmacy Programs; IC: Integrated Course; MENA: Middle East and North Africa; P1: Professional Year 1; P2: Professional Year 2;

P3: Professional Year 3; P4: Professional Year 4; TEL: Technology Enhanced Learning; VLE: Virtual Learning Environment

\section{Acknowledgements}

Not applicable.

\section{Authors' contributions}

FNH, AAG and RM conceived and conceptualized the study design with the assistance of MD. All authors analyzed and interpreted the data and prepared, revised, and approved the manuscript.

\section{Funding}

This research did not receive any specific grant from funding agencies in the public, commercial, or not-for-profit sectors.

\section{Availability of data and materials}

The datasets generated and/or analysed during the current study are available from the corresponding author on reasonable request.

\section{Competing interests}

The authors declare that they have no competing interests in this section.

Received: 21 February 2020 Accepted: 11 May 2020

Published online: 18 September 2020

\section{References}

Bacro, T. R., Gebregziabher, M., \& Fitzharris, T. P. (2010). Evaluation of a lecture recording system in a medical curriculum. Anatomical Sciences Education, 3(6), 300-308. https://doi.org/10.1002/ase.183.

Burton, W.B., Ma, T.P., \& Grayson, M.S. (2017). The relationship between method of viewing lectures, course ratings, and course timing. Journal of Medical Education and Curricular Development, 4, 2382120517720215. doi: https://doi.org/10. $1177 / 2382120517720215$

Casanova, D., Moreira, A., \& Nilza, C. (2011). Technology enhanced learning in higher education: Results fromthe design of a quality evaluation framework. Procedia - Social and Behavioral Sciences, 29, 893-902. https://doi.org/10.1016/j.sbspro.2011. 11.319 .

Chester, A., Buntine, A., Hammond, K., \& Atkinson, L. (2011). Podcasting in education: Student attitudes, behaviour and SelfEfficacy. Educational Technology \& Society, 14(2), 236-247.

Copley, J. (2007). Audio and video podcasts of lectures for campus-based students: Production and evaluation of student use. Innovations in Education and Teaching International, 44(4), 387-399. https://doi.org/10.1080/14703290701602805.

Corrin, L., Lockyer, L., \& Bennett, S. (2010). Technological diversity: An investigation of students' technology use in everyday life and academic study. Learning, Media and Technology, 35(4), 387-401. https://doi.org/10.1080/17439884.2010.531024.

DeRuisseau, L. R. (2016). The flipped classroom allows for more class time devoted to critical thinking. Advances in Physiology Education, 40(4), 522-528. https://doi.org/10.1152/advan.00033.2016.

Dommeyer, C. J. (2017). Lecture capturing: Its effects on students' absenteeism, performance, and impressions in a traditional marketing research course. Journal of Education for Business, 92(8), 288-295. https://doi.org/10.1080/08832323.2017. 1398129.

Fernandes, L., Maley, M., \& Cruickshank, C. (2008). The impact of online lecture recordings on learning outcomes in pharmacology. Journal of the International Association of Medical Science Educators, 18(2), 62-70.

Franklin, D. S., Gibson, J. W., Samuel, J. C., Teeter, W. A., \& Clarkson, C. W. (2011). Use of lecture recordings in medical education. Medical Science Educator, 21, 21-28. https://doi.org/10.1007/BF03341590.

Freeman, M. K., Schrimsher, R. H., \& Kendrach, M. G. (2006). Student perceptions of online lectures and WebCT in an introductory drug information course. American Journal of Pharmaceutical Education, 70(6), 126. https://doi.org/10.5688/ aj7006126.

Gupta, A., \& Saks, N. S. (2013). Exploring medical student decisions regarding attending live lectures and using recorded lectures. Medical Teacher, 35(9), 767-771. https://doi.org/10.3109/0142159X.2013.801940.

Hamilton, L. A., Franks, A., Heidel, R. E., McDonough, S. L., \& Suda, K. J. (2016). Assessing the value of online learning and social Media in Pharmacy Education. American Journal of Pharmaceutical Education, 80(6), 97. https://doi.org/10.5688/ ajpe80697.

Hussain, F. N., \& Wilby, K. J. (2019). A systematic review of audience response systems in pharmacy education. Currents in Pharmacy Teaching and Learning, 11(11), 1196-1204. https://doi.org/10.1016/j.cptl.2019.07.004.

Marchand, J. P., Pearson, M. L., \& Albon, S. P. (2014). Student and faculty member perspectives on lecture capture in pharmacy education. American Journal of Pharmaceutical Education, 78(4), 74. https://doi.org/10.5688/ajpe78474.

Maynor, L. M., Barrickman, A. L., Stamatakis, M. K., \& Elliott, D. P. (2013). Student and faculty perceptions of lecture recording in a doctor of pharmacy curriculum. American Journal of Pharmaceutical Education, 77(8), 165. https://doi.org/10.5688/ ajpe778165.

McLean, J. L., \& Suchman, E. L. (2016). Video lecture capture technology helps students study without affecting attendance in large microbiology lecture courses. Journal of Microbiology \& Biology Education, 17(3), 480-481. https:/doi.org/10.1128/ jmbe.v17i3.1123. 
O'Callaghan, F. V., Neumann, D. L., Jones, L., \& Creed, P. A. (2017). The use of lecture recordings in higher education: A review of institutional, student, and lecturer issues. Education and Information Technologies, 22(1), 399-415. https://doi.org/10. 1007/s10639-015-9451-z.

Owston, R., Lupshenyuk, D., \& Wideman, H. (2011). Lecture capture in large undergraduate classes: Student perceptions and academic performance. The Internet and Higher Education, 14(4), 262-268. https://doi.org/10.1016/j.iheduc.2011.05.006.

Schnee, D., Ward, T., Philips, E., Torkos, S., Mullarkey, J., Tataronis, G., \& Felix-Getzik, E. (2019). Effect of live attendance and video capture viewing on student examination performance. American Journal of Pharmaceutical Education, 83(6), 6897. https://doi.org/10.5688/ajpe6897.

Stroup, M. D., Pickard, M. M., \& Kahler, K. E. (2012). Testing the effectiveness of lecture capture technology using prior GPA as a performance indicator. Teacher-Scholar: The Journal of the State Comprehensive University, 4(1), 43-54.

Traphagan, T., Kucsera, J. V., \& Kishi, K. (2010). Impact of class lecture webcasting on attendance and learning. Educational Technology Research and Development, 58(1), 19-37. https://doi.org/10.1007/sl 1423-009-9128-7.

Tune, J. D., Sturek, M., \& Basile, D. P. (2013). Flipped classroom model improves graduate student performance in cardiovascular, respiratory, and renal physiology. Advances in Physiology Education, 37(4), 316-320. https://doi.org/10.1152/ advan.00091.2013.

\section{Publisher's Note}

Springer Nature remains neutral with regard to jurisdictional claims in published maps and institutional affiliations.

Submit your manuscript to a SpringerOpen ${ }^{\odot}$ journal and benefit from:

- Convenient online submission

- Rigorous peer review

- Open access: articles freely available online

High visibility within the field

Retaining the copyright to your article

Submit your next manuscript at $\boldsymbol{\nabla}$ springeropen.com 